\title{
Complexity in the Kitchen
}

\author{
Joseph T. Foley ${ }^{1, \star}$, Lindy Puik², Erik Puik ${ }^{3}$, Joseph Smith ${ }^{4}$, and David S. Cochran ${ }^{4}$ \\ ${ }^{1}$ Reykjavik University, Menntavegur 1, Reykjavik 101, Iceland \\ ${ }^{2}$ Matterhorn 15, 5624 NR Eindhoven, The Netherlands \\ ${ }^{3}$ TU Utrecht, Hudsondreef 32, 3565 AV Utrecht, The Netherlands \\ ${ }^{4}$ Purdue University — Fort Wayne 2101 E. Coliseum Blvd., ETCS 229B, Fort Wayne, Indiana, USA
}

\begin{abstract}
Axiomatic Design and Complexity theory are often applied to highly complex and technological systems which provide educators with many engineering examples and case studies. The use of Axiomatic Design is applicable outside of these areas. However, there are not many examples outside of these areas. As a result, students often have trouble understanding the breadth and impact of Axiomatic Design's application to problem-solving. One large complex system that is often overlooked is that of the kitchen. In this paper, we present different food-related preparation tasks that are inherently complex: cooking a turkey, baking an apple pie, reverse-engineering a recipe, and designing ecologically-minded food packaging while also discussing the impact of prepared food's packaging approaches on the environment. The authors believe such examples demonstrate Axiomatic Design's applicability in a new aspect that is approachable to a wide audience.
\end{abstract}

\section{Introduction}

Axiomatic Design has been used in highly technical realms and creative areas. Technical applications include: Shape Memory Allow actuator testing [1], Industry 4.0 Human-Robot interfacing [2], industrial safety practices [3], and re-configurable manufacturing system design at Mercedes-Benz [4]. Nontechnical interest comes in the areas of football ${ }^{1}$ [5], diabetes treatment [6], university department organization [7,8], special education curricula [9] and interactive art [10]. This paper provides case studies and analogies that are relevant to engineering students and the technically literate. Unfortunately, for those who wish to use axiomatic design outside of those fields, educators are left with examples that resonate with engineering students, but not with the design and student community at large. The non-technical analogy most commonly used by educators is that of designing a water faucet that is easy to use. This example was initially published by Suh [7] and further expanded and revised by Foley [11].

One area that contains highly technical challenges that are approachable by a large audience is that of food preparation. In "On Food and Cooking", Harold McGee celebrates that the worlds of science and culinary arts have become tightly integrated and collaborative since he first wrote the work that has brought him fame [12]. The authors agree that this indicates that it is an excellent area to exploit for interdisciplinary research while also providing rich examples to use in teaching design. The idea of using food preparation as a design exercise is not unique:

\footnotetext{
^e-mail: foley@ru.is

${ }^{1}$ Also known in the US as Soccer, which is distrinct from what some might call "hand-egg"
}

Slocum [13] uses cooking dinner as one of his common examples in his modified Axiomatic Design method called FRDPARRC. Cooking itself is a transformative process, which fits well within the Functional Requirement mapping to Physical Requirement aspect of Axiomatic Design: these terms will be explained in more detail in the next section.

\subsection{Axiomatic Design}

Axiomatic Design's basic premise is that design is primarily concerned with mapping between domains as shown in Figure 1. The customer to functional domain mapping is a significant focus in the area of product design as treated in Ulrich and Eppinger [15]. Suh's books [7, 16, 17] primarily focus on the mappings between functional and physical, occasionally exploring the process domain. He noticed that there were two commonalities often found in designs that were successful. These were codified into two axioms: [7].

Independence Axiom (1): "maintain the independence of the functional requirements (FRs)"

Information Axiom (2): "minimize the information content of the design"

To better understand what these axioms mean, we consider an additional element in the Axiomatic Design process. As part of analyzing the interactions between domains, a design matrix is created, which is a Cartesian product of all FR and DP combinations [18, 19]. Where there is an interaction between an FR and Design Parameter (DP), this is denoted by a non-zero coefficient, or in 


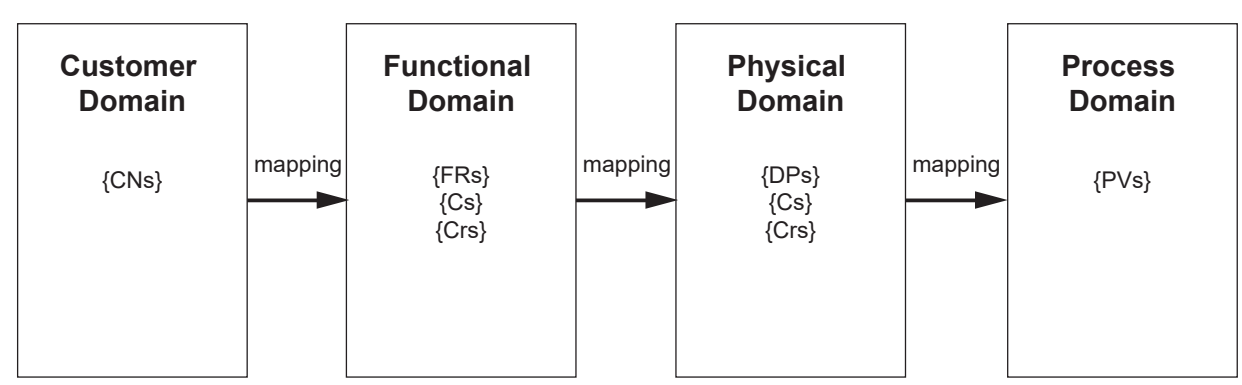

Figure 1: Axiomatic Design Domain Mapping (Reproduced from [14] with permission, based upon [7, p.11])

the case of the value being unknown, simply a placeholder variable $X$. Minor levels of coupling, often considered higher-order effects, are annotated with $x$ to show their lessened effect. A diagonal matrix is "uncoupled" and satisfies the Independence Axiom: "to maintain the independence of the functional requirements (FRs)" [7]. Such a design can be easily optimized by adjusting a particular FR or DPs without affecting others. A triangular matrix indicates a "decoupled" or "path-dependent" solution, which can still be optimized, but the ordering of parameter choice selection becomes important. All other design matrices are "coupled" and may have a usable local solution but usually resist modification and optimization [7]. Needless to say, the focus is on minimizing coupling wherever it may appear [20].

Axiomatic Design Theory's (ADT's) second axiom is "minimize the information content of the design". Simply put, ensure that the design has the highest probability of meeting the stated FRs. When systems are not able to meet FRs all of the time, this is denoted in ADT as "complexity" and is deeply explored in [17]. Suh's formal definition of Information is described in Section 1.2.

Finally, any factors to be considered that are not functional are categorized as "Constraints". These are often resource-focused and affect all of the design decisions; they need to be revisited often especially when choosing between otherwise equivalent implementations [7, 20].

From this mapping we develop a design matrix as shown in Equation 1:

$$
\left\{\begin{array}{l}
\mathrm{FR}_{1} \\
\mathrm{FR}_{2} \\
\mathrm{FR}_{3}
\end{array}\right\}=\left[\begin{array}{ccc}
X & 0 & X \\
0 & X & 0 \\
0 & 0 & X
\end{array}\right]\left\{\begin{array}{l}
\mathrm{DP}_{1} \\
\mathrm{DP}_{2} \\
\mathrm{DP}_{3}
\end{array}\right\}
$$

This design matrix is partially coupled or de-coupled due to it being triangular. This means that the order of sequence of implementation matters. For this reason, the design is path or sequence dependent. If the design matrix has only elements on the diagonal, it is "uncoupled"indicating that the order does not matter. Finally, if the matrix cannot be put into a diagonal or triangular form, it is coupled, meaning that it is much more difficult to optimize and adjust as per Axiom 1.

The authors have found that the axioms are often confusing to beginning practitioners of the design discipline and to non-technical parties of interest. Joe Foley pre- sented these at the ICAD2017 tutorials in a zen koan riddle [21]:

Independence Axiom (1): Find harmony in conflict

Information Axiom (2): Prepare for the unexpected

One might clarify this explanation further:

Independence Axiom (1): Modularize

Information Axiom (2): Choose robust elements and their combinations

In addition to mapping, each element in a domain is decomposed to break the "problem" into manageable pieces. The decomposition is managed in a "zig-zag" method: complete a current level of decomposition, mapping it to the next domain, then returning to the previous domain to expand it further. This process and the documentation created during its execution are the highly desired "design intent" as it contains the interactions between decisions codified in a compact format.

\subsection{Complexity Theory}

In an effort to simplify the understanding of how many reliability (primarily Axiom 2) issues can be addressed, Suh's later focus combines the AD concepts into a singular Complexity Theory [17].

He explores the meaning of complexity, finally settling on "Complexity is defined as a measure of uncertainty in achieving the specified FRs" [14, 17, p.58]. This definition is then subdivided into four different types:

time-independent real complexity which is simply the information content of a design: $C_{R}=I$, where $I_{i}=$ $-\log _{2} P_{i}$ and $P_{i}$ is the probability of meeting satisfying $\mathrm{FR}_{i}$. For uncoupled designs, the total information of the system is simply the sum $I=\sum_{i} I_{i}$. For other cases, we refer the reader to Suh's deeper descussion in [17].

time-independent imaginary complexity arises in coupled or path-dependent solutions where the order in which DPs should be addressed is unclear or improperly ordered.

time-dependent combinatorial complexity develops in systems in which operation has a higher probability of going out of specification due to "continued expansion in the 
number of possible combinations with time". In short, time-dependent combinatorial complexity describes systems that progress toward chaotic states over some time period.

time-dependent periodic complexity is similar to combinatorial complexity except that a functional period has been identified over which the system can be reset before it enters an unpredictable state.

These four categories of complexity provide a generalization and quantification of the predicted reliability of a design based upon the operating specifications and analysis of coupling during the design phase. Suh also provides guidelines for reducing these types of complexity: see [17] for an in-depth discussion of this topic [14].

The majority of his efforts in [17] focus on how complexity arises due to challenges in the Functional Requirements. Vossebeld et al. [14] consider a wider scope of how complexity can creep into designs by considering the effect various Customer Need complexities can have on a design process. In cooking, the focus is on the result meeting an often hard-to-describe need (other than nourishment) so a better understanding of these is required. Foley and Harðardóttir [10] explores how to apply Axiomatic Design on creative endeavors, suggesting that an "latent needs" approach similar to Ulrich and Eppinger [15] may be helpful in dealing with such needs. Needs may need to be abstracted to emotions or experiences before being transformed into requirements. In some cases, the needs may not even become clear until an initial round of evaluation of a prototype in which case hidden Customer Needs and Functional Requirements may need to be back-solved as discussed by Girgenti et al. [22].

\subsection{Cooking Science}

Harold McGee wrote one of the seminal works in trying to bridge the gap between cooking and science in his work "On Food and Cooking" in 1984 later revised in 2004 [12, 23]. This book is considered one of the required texts for those interested in the science behind food and the cooking processes considered commonplace today. When the book was first introduced, technical terms such as "emulsified" and "denatured" were foreign to chefs except perhaps those previously schooled in chemistry [23]. McGee's book is highly relevant to this article due to its focus on a deeper understanding of how food and cooking processes interact. To Axiomatic Design practitioners, the word "interact" should instantly remind us of the concept of "coupling" and for good reason.

\section{Complex Recipes}

The AD axioms take a different cast when trying to cook

Independence Axiom (1): Reduce interaction between ingredients and processes to only the ones desired

Information Axiom (2): Produce the desired food aspect reliably
Of note, there is one fast food chain that is famous for mastering Axiom 2 on a global basis: the McDonald's corporation. It is well known to the point of an adage that "A McDonald's hamburger is the same no matter where you are". The unspoken secondary part is that they are consistent, but not considered high quality i.e. "consistent mediocrity" [24]. In section 5, we examine a structured way to evaluate the quality of a cooking result particularly for "complex" recipes.

\section{Cooking a Turkey}

In the United States, the holiday known as Thanksgiving is associated with roasting a turkey in modern times (Figure 2). How this came to be is a fascinating story which we will explore in brief ${ }^{2}$.

\subsection{Why does US Thanksgiving mean eating a turkey?}

The word turkey for the bird we know came into use during the Middle Ages. Its origins are best explained as being associated with the Turkish Empire being the main European trade route from which exotic birds such as the peafowl were arriving [25, p. 28].

Three centuries before any actual turkeys appeared in 16th-century Europe, the word turkey was being used to describe exotic birds from Asia [27, p. 16].

${ }^{2}$ An excellent resource on Thanksgiving's turkey tradition is Davis's "More than a Meal" [25] which provided much of our historical resources and may convince some readers to go vegan.

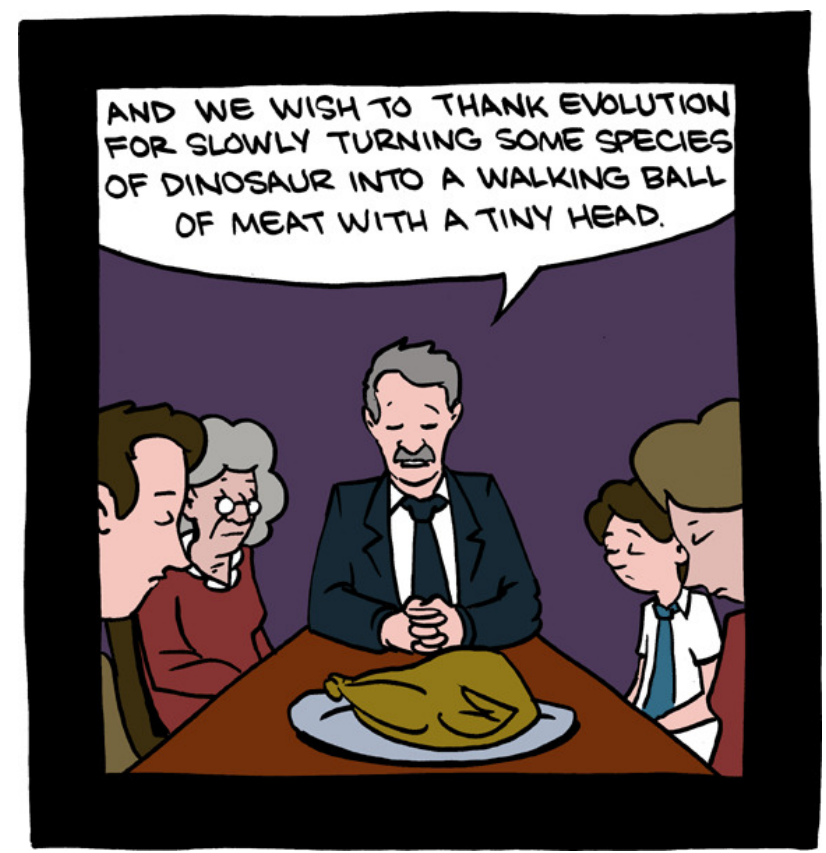

Figure 2: The annual US Thanksgiving tradition of roasting a turkey by Zach Weinersmith [26]. Reproduced with permission. 
The choice of it being a roasted bird (Figure 2) in the United States are clear due to it being plentiful, especially in the New England area where the Puritan settlers arrived [25, p. 33]. That said, records of the feast from the first Thanksgiving mention a large variety of birds but no specific mention of turkey [28, p. 100]. Thanksgiving was not a significant national holiday in the US until 1863 when President Abraham Lincoln used it as a mechanism to promote unity [25, p. 53]. Alexander Hamilton, the first secretary of the Treasury is perhaps the earliest proponent of turkey being critical to Thanksgiving, saying "[n]o citizen of the United States should refrain from turkey on Thanksgiving Day" in 1805 [27, p. 369][25, p. 53]. By 1857, it had become a traditional part of Thanksgiving in New England. The English had an even earlier introduction to Turkey in 1573 , being referred to as "Christmas husbandlie fare" [29, p. 338][25, p. 54]. The bird had been shipped there from Mexico by Spanish explorers in the 16th century and became commonly bread during Renaissance England [25, p. 54]. Strangely enough, the breeds that made their way there were then brought back to the US to become the forerunner of modern domesticated turkey breeds [25, p. 54]. In short, the patriotic United States holiday Thanksgiving, strangely enough, is all about devouring a Latin-America repatriated bird species!

\subsection{Bringing the bird to the table}

The challenge of cooking a turkey in a consistent way was deeply considered in a periodical up in November 1993 by the cooking journal Cooks Illustrated ${ }^{3}$.

Anyone who has tried to cook a frozen turkey in any reasonable amount of time has run into the problem of having the meat cooked thoroughly while also remaining juicy. The problem stems from a few factors:

- A frozen turkey requires a huge amount of energy to heat the center.

- A large turkey has a large amount of thermal mass. (16 kg or greater)

- The turkey is not homogeneous, so the various parts cook at different rates.

- The US Department of Agriculture recommends an internal temperature of at least $165^{\circ} \mathrm{F}\left(73.9^{\circ} \mathrm{C}\right)$ to "destroy bacteria and prevent food-borne illness" [31]

Rather than focus on the details of meat thermal models which have already been explored in [32-34], we place our attention on the overall design aspect. McGee [12] discusses the challenge of roasting whole birds including chickens and turkeys. He agrees that the challenge is that the meats are "best cooked differently". Breast meat becomes an unpleasantly chewy and tough texture to the palate if cooked much over $68^{\circ} \mathrm{C}$. Conversely, the leg and other dark meat have significant connective tissue that is chewy at temperatures below $72^{\circ} \mathrm{C}$. We have a contradiction, similar to what the Russian design methodology TRIZ [35] delights in; what is a cook to do?

\footnotetext{
${ }^{3}$ The first reference to analyzing turkey storage and cooking the authors were able to find was from 1962 in [30].

${ }^{4}$ who is a co-author on one of the meat thermal models
}

Rather than be distracted by TRIZ's enthusiasm, let us consider the problem in an Axiomatic Framework:

- $\mathrm{FR}_{1}$ Heat breast meat to a maximum $68^{\circ} \mathrm{C}$.

- $\mathrm{FR}_{2}$ Heat thigh meat to a minimum $72^{\circ} \mathrm{C}$.

Traditionally, cooks have tried to solve this with a single DP, which results in the design matrix shown in Equation 2.

- $\mathrm{DP}_{1}$ Heated enclosure at $180^{\circ} \mathrm{C}$ for $\mathrm{X}$ minutes per $\mathrm{kg}$

$$
\left\{\begin{array}{l}
\mathrm{FR}_{1} \\
\mathrm{FR}_{2}
\end{array}\right\}=\left[\begin{array}{l}
X \\
X
\end{array}\right]\left\{\mathrm{DP}_{1}\right\}
$$

Clearly, this will have issues: There is a single DP for 2 FRs, so it is inherently coupled. In addition, the chances of meeting both FRs are very low since breast's and thighs are both at the surface and have varying thicknesses. Perhaps we could change the thickness of the meat, choosing turkeys with thicker breasts and following the thermal transfer model derived by [34]. Unfortunately, measuring the exact size of the turkey breast without removing it is rather challenging, so this approach is abandoned.

One other thought is to compress our FRs:

- $\mathrm{FR}_{1}$ Heat breast and thigh meat to a individual optimal temperatures

Which does not show unreasonable coupling due to it being a 1FR1DP design (Equation 3), but has a large information content because the two temperatures are different.

$$
\left\{\mathrm{FR}_{1}\right\}=[X]\left\{\mathrm{DP}_{1}\right\}
$$

An obvious improvement is to add feedback:

- $\mathrm{DP}_{1}$ Heated enclosure at $180^{\circ} \mathrm{C}$

- $\mathrm{DP}_{2}$ Thermometer

Unfortunately, this still won't work because of the contradiction. Clearly, we need to uncouple the two FRs somehow. One answer is to physically uncouple them with a kitchen knife as shown in Figure 3:

- $\mathrm{FR}_{1}$ Separate meat pieces according to dark vs. light meat.

- $\mathrm{FR}_{2}$ Heat each type of meat to the optimal temperature

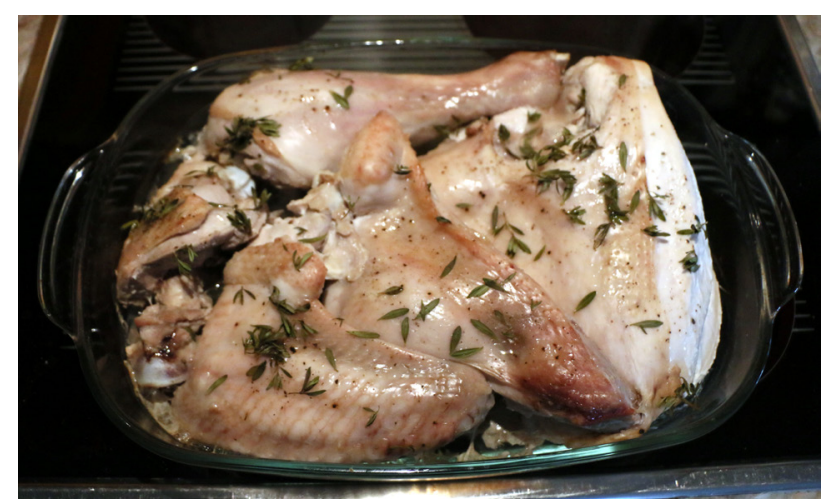

Figure 3: The author's interpretation of un-coupling a turkey's anatomy to reduce the cooking complexity. 


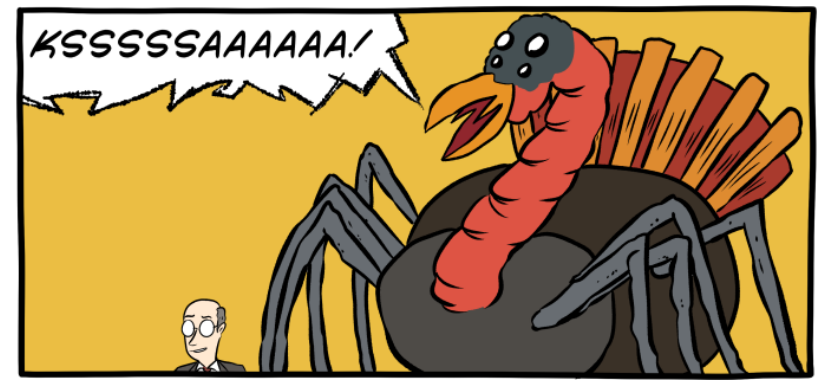

Figure 4: The Spidurky: a method of increasing drumstick availability by Zach Weinersmith [36]. Reproduced with permission.

- $\mathrm{FR}_{2.1}$ Heat breast meat to maximum of $68^{\circ} \mathrm{C}$.

- $\mathrm{FR}_{2.2}$ Heat thigh meat to a minimum $72^{\circ} \mathrm{C}$.

- $\mathrm{DP}_{1}$ Knife and knowledge of turkey anatomy

- $\mathrm{DP}_{2}$ Heated enclosure at $180^{\circ} \mathrm{C}$ and thermometer probe in meat

The resulting design matrix in Equation 4 is decoupled or "path-dependent" indicating that we must do things in the correct order. Clearly we have to cut the turkey before we can put it into the oven.

$$
\left\{\begin{array}{l}
\mathrm{FR}_{1} \\
\mathrm{FR}_{2}
\end{array}\right\}=\left[\begin{array}{ll}
X & 0 \\
X & X
\end{array}\right]\left\{\begin{array}{l}
\mathrm{DP}_{1} \\
\mathrm{DP}_{2}
\end{array}\right\}
$$

This new configuration greatly reduces the information content (Axiom 2) because the temperature of each type of meat can be carefully controlled. Seeing that people seem to prefer some parts of the turkey more than others, this seems like a very simple way to uncouple. Unfortunately, such desirability of a particular type or part of the meat such as the often desired drumstick can result in decisions that lead to the terrifying implications supposed in Figure 4.

One must not forget the heat transfer aspect of cooking in an oven: the outside temperature of a cut of meat will be much higher than the target temperature unless special care is taken to remove the meat from the oven before it reaches the target temperature for "carry-over" cooking.

To further reduce the chances of failure, we can take a lesson from the current food movement of Sous-vide water baths similar to the Paté cooking described by [12, p. 171]:

- $\mathrm{FR}_{1}$ Heat breast meat to a maximum $68^{\circ} \mathrm{C}$.

- $\mathrm{FR}_{2}$ Heat thigh meat to a minimum $72^{\circ} \mathrm{C}$.

- $\mathrm{DP}_{1}$ Immerse plastic-sealed breast meat chunks in $68^{\circ} \mathrm{C}$ water until equilibriated

- $\mathrm{DP}_{2}$ Immerse plastic-sealed breast meat chunks in $72{ }^{\circ} \mathrm{C}$ water until equilibriated

It would seem that we have found the perfect turkey cooking method, and in fact, this is similar to what is done to cook turkey meat in restaurants when it is used as a component or covered in sauces. Unfortunately, we have not considered our customer's needs carefully enough as in $[14,22]$. The customers want the food to be presented in a particular way, not just be at the correct temperature.
- $\mathrm{CN}_{1}$ Put a cooked whole bird on the table so it looks pretty

- $\mathrm{CN}_{2}$ The skin must be crispy

We need some way to cook certain parts of the bird selectively to address these needs without going back into our coupled state and without mechanically separating them.

\subsection{How do people really cook a turkey?}

A number of innovative solutions have arisen to address these challenges to varying degrees. With minimal effort, one can find videos and equipment for deep-fatfrying a turkey to speed up the process, obvious even in 1962 [12][30]. While faster, this greatly increases the chances of injury as the ice crystals (or just moisture) cause the hot oil to atomize, occasionally turning the cooker into a fireball of epic proportions [37, 38]. The issue is a large enough concern that there is a patent on a deep fryer that claims to make this process safer by Osias [38].

Defrosting the turkey ahead of time also can assist, if planning permits. This does not address the problem of the differing composition of dark and white meat resulting in certain parts cooked while the others are not. Again, necessity has bred innovation in the form of placing aluminum foil as a radiant heat shield over the white meat areas. One suggestion was to place ice packs over the white meat to cook them selectively. As well as some of these approaches work, they still require significant effort and quite a bit of skill to apply for repeatable success. This makes it clear that cooking the turkey is clearly a "complex system" in the Suh sense.

The concept of brining a turkey was the initial issue of Cooks Illustrated in 1993 since updated in 2004 [39]. Very recently, Lan Lam, Senior Editor of "Cook's Illustrated" re-examined the turkey process to see if the process could be further streamlined in [40]. Brining a turkey allows us to remove the contradiction inherent in our two incompatible target temperatures by changing the meat chemistry in a way that it can accept a larger variety of temperatures and maintain a high level of moisture. This wider range of acceptable temperatures could be considered "softening the spring" in Suh's terminology. Lam's improved recipe replaces the short brining with a long refrigerated salting step, which accomplishes the same goal and reduces the moisture to improve the skin's crispiness. Doing this with a small amount of sugar also caused the skin to brown nicely, effectively caramelizing in the skin.

The previous recipe suggested starting the turkey upside down so that the majority of the heat focused on the dark meat (on the bottom of the bird). Lam wanted to find an easier way to apply more heat to the bottom without the extra effort and found it in the current method of making pizza at home: a pizza stone. This large stone, when preheated correctly, stored enough heat that the turkey could simply be placed in the roasting V-rack and not have to be manipulated. This innovation caused the dark and light meat to finish cooking at the same time. 
- $\mathrm{FR}_{1}$ Keep white meat tender at $72^{\circ} \mathrm{C}$ and higher

- $\mathrm{FR}_{2}$ Crisp skin of turkey

- $\mathrm{FR}_{3}$ Heat meat to $72^{\circ} \mathrm{C}$

- $\mathrm{DP}_{1}$ Brine (changes protein structure of meat to retain water)

- $\mathrm{DP}_{2}$ Sugar solution

- $\mathrm{DP}_{3}$ Preheated pizza-stone, heated enclosure at $180^{\circ} \mathrm{C}$, and thermometer probe in meat

In effect, the new procedure is effectively uncoupled as shown in Equation 5. Each of the FRs is only affected by its DP.

$$
\left\{\begin{array}{l}
\mathrm{FR}_{1} \\
\mathrm{FR}_{2} \\
\mathrm{FR}_{2}
\end{array}\right\}=\left[\begin{array}{ccc}
X & 0 & 0 \\
0 & X & 0 \\
0 & 0 & X
\end{array}\right]\left\{\begin{array}{l}
\mathrm{DP}_{1} \\
\mathrm{DP}_{2} \\
\mathrm{DP}_{3}
\end{array}\right\}
$$

As can be easily seen, the continuing innovation in cooking a challenging roast such as a turkey involves understanding the coupling and information content inherent in each of the process choices made for having it arrive on the Thanksgiving table.

\section{Baking an Apple Pie}

A famous simile often used in the US is "As American as Apple Pie". This references the idolized atomic-family period of the 1950s where the working spouse would arrive home to the smell of a freshly baked apple pie (Figure 5).

The concept of a pie and apples themselves did not originate in the US [42]. In fact, the association seems to have come about due to WW2 involvement by the US [43]. One of the author's own experience in baking pies allowed him to immediately identify what makes them challenging when following the traditional approach.

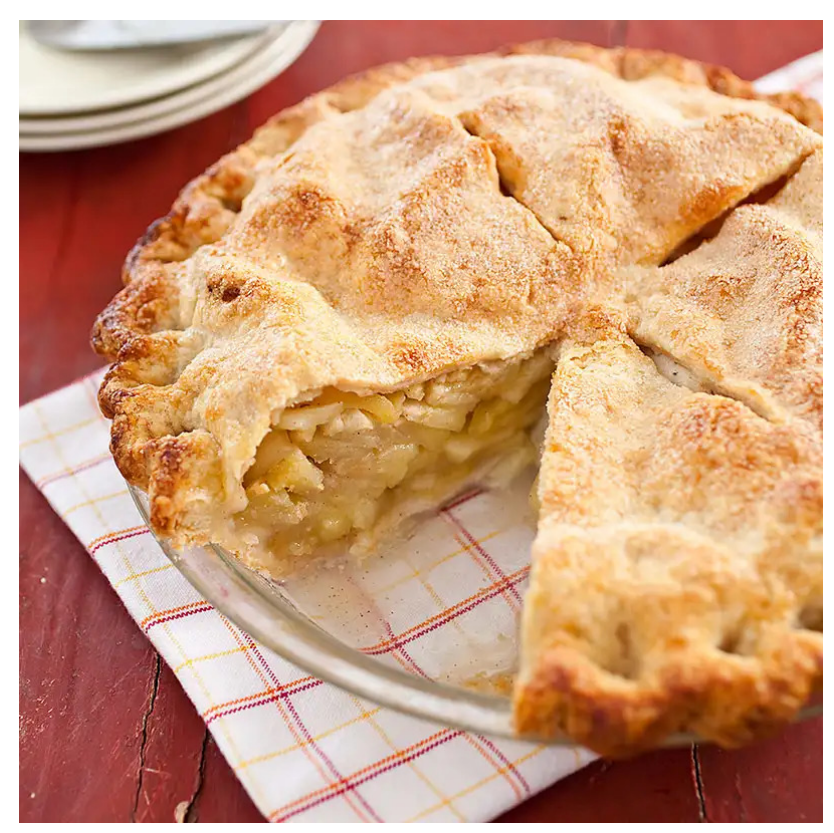

Figure 5: A classic apple pie. Image reproduced with permission from America's Test Kitchen [41]
- $\mathrm{CN}_{1}$ Top and bottom crusts should be flaky

- $\mathrm{CN}_{2}$ Crust should hold the fruit in but not be thick like pizza

- $\mathrm{FR}_{1}$ Separate many small blobs of fat and wheat flour

- $\mathrm{FR}_{2}$ Roll crust to consistent thickness of $3 \mathrm{~mm} \pm 1 \mathrm{~mm}$

- $\mathrm{DP}_{1}$ Butter cut into flour at a cold temperature until peasized lumps form, then made into a ball and rolled out.

- $\mathrm{DP}_{2}$ Water added until it can be manipulated with a rolling pin

The problem comes clear when examining the design matrix in Equation 6.

$$
\left\{\begin{array}{l}
\mathrm{FR}_{1} \\
\mathrm{FR}_{2}
\end{array}\right\}=\left[\begin{array}{ll}
X & X \\
X & X
\end{array}\right]\left\{\begin{array}{l}
\mathrm{DP}_{1} \\
\mathrm{DP}_{2}
\end{array}\right\}
$$

This concept is coupled because the water affects the layers of the starch and fat. If you do not add enough water, the dough is hard to work with: it does not stay together, crumbles, and is very fragile. If you add too much water, the dough is no longer flaky when baked. The more you manipulate the mixture, the more gluten forms and it gets leathery in texture.

In addition, unless the cook is able to work in a refrigerator, the butter will begin to melt as it is worked. This creates a time dependence and reduces the chances of success. Depending upon your dietary preferences or desired tastes, you can use hydrogenated vegetable shortening, coconut oil, or even traditional lard [44]. Many of these fats fix the melting problem but does not have much taste, so some butter needs to be added back in.

What we need is a different fluid that does not interact with starch and fat to eliminate coupling. The choices of liquid in the standard kitchen are limited to mostly waterbased hydrolysates and oils. Pastry already has a fat, so additional oil will affect the butter-starch interaction. Julia Childs comes to the rescue in the form of the only other commonly available liquid: alcohol [44]. Alcohol acts similar to water at room temperature but disappears at oven baking temperatures. In addition, alcohol inhibits the gluten-forming process, ensuring that flakiness is preserved as you work the dough into shape as shown in Figure 6.
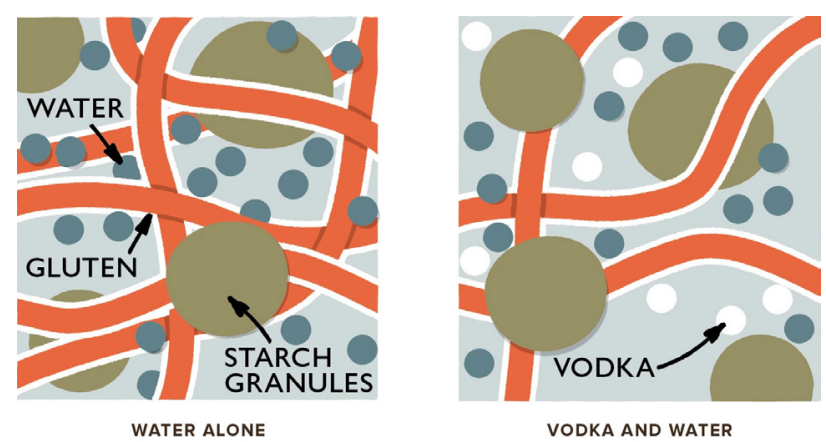

Figure 6: Effect of alcohol on pie dough. Image reproduced with permission from America's Test Kitchen [44] 
These changes affect our DPs:

- $\mathrm{DP}_{1}$ High-melting temperature fat with low moisture content cut into flour at a cold temperature until peasized lumps form, then made into a ball and rolled out.

- $\mathrm{DP}_{2}$ Vodka added until it can be manipulated with a rolling pin

$$
\left\{\begin{array}{l}
\mathrm{FR}_{1} \\
\mathrm{FR}_{2}
\end{array}\right\}=\left[\begin{array}{ll}
X & 0 \\
0 & X
\end{array}\right]\left\{\begin{array}{l}
\mathrm{DP}_{1} \\
\mathrm{DP}_{2}
\end{array}\right\}
$$

As shown in the Design Matrix in Equation 7, these two small changes have reduced complexity by removing coupling between the various elements, increasing the chances that we will meet our requirements.

\section{The Complexity of Reverse Engineering a Recipe}

The complexity of cooking becomes painfully clear when a recipe needs to be reversed engineered. Typical examples of this are found in a cooking show produced by Endemol, "Herman Against the Others" (inspired by the German show "Kitchen Impossible"), in which top chef Herman den Blijker challenges known and award-winning chefs to reproduce a foreign regional signature dish. A third foreign award-winning chef prepares the pretty complicated signature dish, typically a regional specialty, and challenges Herman and his opponent to reproduce it. The chefs have no or little experience in preparing it, as it is a regional dish that does not meet their expertise. By tasting the food and observing its structure and characteristics, they have to find out what the exact ingredients are and determine the right procedure for preparation. They can taste the dish, take pictures, ask employees in stores and/or ask people in the streets. Obviously, time is limited so they have to apply readily available knowledge for reproduction. The competing chefs both present their dish to a qualified local jury consisting of 6 to 8 local experts that will taste the dish, assess and rate it. As the cooking show presents a battle between top chefs, complexity is desired to make the show interesting for its viewers. This is not unique as there are situations where complexity is desirable [45]. However, complexity should be reduced by the acquisition of knowledge at the end of the show [46, 47]. A few typical situations are described and analyzed from a perspective of complexity in Axiomatic Design.

The Axiomatic Maturity Diagram (AMD) [48] will be applied to visualize the processes, analyze the scores, and explain the complexity of the reverse engineering process. The AMD, as applied in Figure 7 to 9 plots the status of the Axioms through the development process (in time). The actual position of design activity in the AMD is determined by the extent to which the Axioms are satisfied. The independence Axiom is plotted on the horizontal axis of the AMD and it describes the organization of a product design or in this case the understanding of the cooking process. The vertical axis plots the Information Axiom which is a measure for the robustness of a product design and in this case, it plots how well the cooking process is executed. The goal of the design process is the top-right dot in the AMD; both axioms are fully satisfied and the design may be considered a "Good Design" [16].

In this paper, the process of cooking is considered to be a design process and the process of reconstructing the dish after reverse engineering is plotted in the AMD. In the cooking show, the chefs' performances are rated with a grade on a scale of $1-10$. To visualize this, the AMD is expanded with scores around the dot at the top right side. The grades of the jury members (a number of 6-8 persons) are averaged into a single score. The open dot at the end of the development path represents the average and final score per dish of the jury (one extra decimal for accuracy on a scale of 0-100). The lines represent the development path that the chefs followed during their quest to reconstruct the dish.

\subsection{Reproduction of Braised Lamb Ribs}

Michelin Guide "Bib Gourmand" awarded Icelandic chef Gísli Matt prepares Lamb Ribs in a sweet and sour sauce. While reverse engineering, the competing chefs are both quite successful in determining the ingredients of this dish. Even the way of preparing the dish is chosen well, both chefs infer that the meat is braised. Unfortunately, the also Michelin Guide "Bib Gourmand" awarded chef Alain Caron, who was born in France and moved to the Netherlands at the age of 26, is mistaken about the exact cut of meat to choose. He chooses a lamb loin instead of the lower ribs. Because of this, his cooking result is not satisfactory. The lamb loin does not have enough fat to make the meat soft during the braising process. His perfect reconstruction of the sweet and sour sauce cannot prevent that his dish is assessed disappointingly by the jury. Alain has made a structural error by selecting a wrong DP (loin instead of ribs). Figure 7 shows the AMD.

The process of reconstructing the dish starts at the lower left of the AMD, where ingredients and preparation method are still unknown. The analysis of the Icelandic dish leads to the organization of the recipe, coupling FRs and DPs, and as such satisfying the Independence Axiom. Unfortunately for chef Alain, the FR "delivering soft but rich mouth feeling" cannot be addressed by the DP "braised lamb loin" because the muscles in the loin are too rigid and will not become soft enough within the available time. In his recipe, the Independence Axiom is not fully satisfied and the curve in the AMD does not reach the right side of the AMD. His perfectly executed sweet and sour sauce brings him quite high in the AMD (correct ingredients that are perfectly treated). His final score is a mere 71 points, while Herman's dish scores 80 points while not being executed to perfection.

\subsection{Reproduction of Scottish Haggis}

The second example is about replication of the Scottish Haggis. Haggis is a savory pudding consisting of sheep's pluck (liver, lungs, heart). It is prepared by Haggis champion and butcher Fraser MacGregor. Herman's opponent 


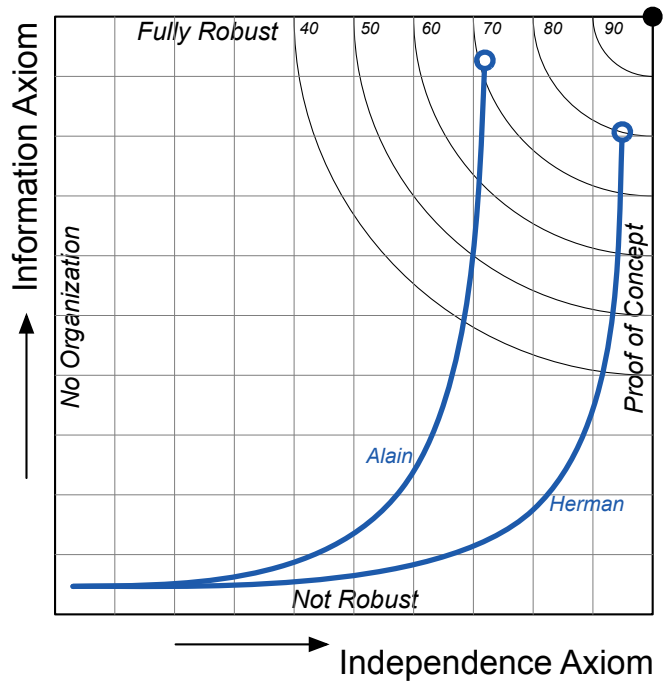

Figure 7: Analysis of chef Alain's mistake. There is a structural error in the design of his recipe. Though the cooking process is executed well, he cannot recover from the mistake, but he minimalizes damage as much as possible

is Maaike Dogan, specialized in merging western and middle eastern food. In this battle, Herman has a substantial advantage; he is familiar with Haggis, recognizes the dish, knows about the ingredients and instantly has ideas to reproduce it. Maaike is not familiar with the dish at all, and she is not able to determine the right ingredients. In fact, she is far off. Instead of using lamb's pluck, she is using minced beef and beef liver. Halfway through the cooking process, it seems that her last chances on a good result are gone when she almost burns her ingredients. This, however, is where the odds turn. Though her ingredients are not the right ones, she shows her excellent cooking skills and qualities in tasting. Due to her middle eastern origin, her skills of seasoning with herbs and spices appear decisive in replicating the right flavor. Where Herman had a big lead, he loses due to the Maaike's excellence in reproducing the right taste. The AMD is shown in Figure 8.

Though Herman's potential is considerably better than Maaike's, Herman gets lower grades due to the incorrect flavor of his dish (68 vs 47 points).

\subsection{Reproduction of Swiss Hay Soup}

The third and last example is the reconstruction of a Swiss 'Hay Soup'. It is a rare Alpine dish usually only served above 1000-2000 meters and made of dried alpine grass, flowers, and herbs. The dish is prepared by top chef Lukas Pfaff by infusing the local hay with water (like preparing hot tea). The hay extract is mixed with beef- or veal and vegetable stock. It is served with a milk-foam and ashes from burnt hay. Herman's opponent is Jermain de Rozario, a young talented and fanatic chef who recently received his first Michelin star.

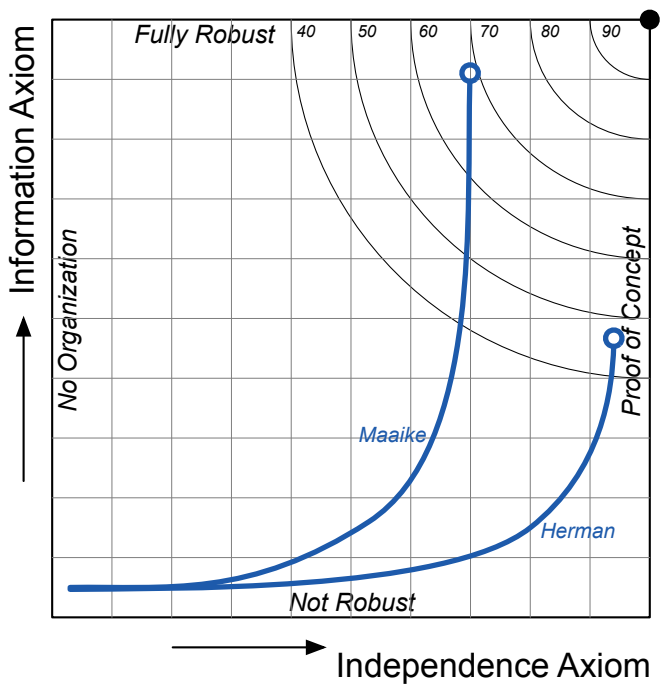

Figure 8: Herman starts off perfectly well, however, though all his ingredients and procedures are perfectly chosen, he is not capable of matching the right flavors and loses the battle

This is a very unusual recipe because hay is an unaccustomed ingredient for soup and the ashes of burnt hay on top of the milk-foam is a challenging attribute to recognize. Both competing chefs are totally unfamiliar with the concept and ingredients of hay soup and have a knowledge making it difficult to properly reproduce it. At this stage Jermain takes a lead; being a young and eager chef he is willing to learn. He has tasted the ashes of hay in the foam because he suspects that hay is used in that part of the soup. Further, he shows two valuable behavioral characteristics:

- He visits a farm to acquire hay and gathers knowledge by asking the farmer about the preparation of the soup. He does the same in the stores he visits. This is how he learns about the right ingredients and the preparation of the soup;

- While preparing the dish, he iterates the recipe of the soup. He tries something, evaluates the result very explicitly and adjusts the recipe to approach the flavors of the soup as close as possible. This is how he improves his recipe a number of times and executes that step again and again. Herman, on the other hand, compiles the soup in a single procedure. Obviously, he tastes a number of times but he does not change his recipe, he continues with what he has cooked in the last step.

Again the AMD of these processes is derived (Figure 9).

Jermain's performance is praised by the jury and they can hardly believe that this soup was made by a different chef since he is so close to the initial dish. His score is a total of 95 points in the AMD. Though Herman has used the right ingredients, his hay is not infused in the right way. The process of infusing took too long and made the soup bitter. His average grade does not go beyond 60 points. 


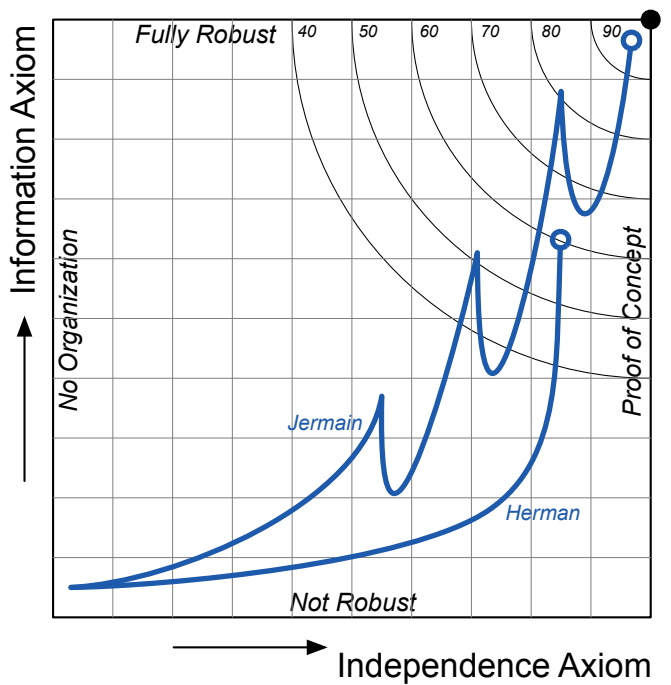

Figure 9: Jermain applies an iterative approach in which he optimizes his recipe several times before he finalizes it. He reflects after every attempt and gathers an understanding of the dish leading to an excellent score

\section{Achieving FRs with Less Waste}

With the move from family-farm centered food distribution to supermarkets, the need for food packaging has increased. In today's busy world, convenience is the name of the game. Disposable, single-serve food items have become a staple at the grocery, and even if you are preparing your own meal at home, many of the ingredients come packaged in a variety of different materials. With an $\mathrm{AD}$ viewpoint, convenience is an FR that is clearly customer-need driven, and the common DP is usually centered around easily disposable packaging.

More recently, sustainable/earth-friendly packaging is becoming an FR born out of the moral and ethical responsibilities felt by the actual consumer of the product. Although this customer need is being driven by the actual consumer of the product, could "The Environment" be the actual customer representing this need? The AD framework provides a way to express the environment as a customer and derive FRs based on the needs of the environment.

For choosing DPs to minimize the impact that a product or process has on the environment, we can use the Design For Environment (DFE) methodology. The DFE methodology provides the means for an organization to minimize the impact of its product and processes on the environment [49] and could aid in choosing more earthfriendly DPs. To understand how adding FRs derived from environmental needs can affect the product design, the first axiom can be used to understand the resulting pathdependency of the design.

One FR could be to, "Ensure product packaging is sustainable". For example, there are many possible DPs that could achieve this requirement such as recyclable materials, biodegradable materials, or even returnable/reusable packaging. The question is what effect does the addition of an FR related to sustainable packaging have on the ability to achieve the other FRs?

Consider the "K-Cup" for a moment [50]. This invention has brought the ultimate convenience to brewing a cup of coffee in the morning, but at the expense of millions of single-use plastic cups hitting the landfill every day. A few companies have recognized this incredible amount of waste and have added an FR to "reduce packaging waste" to their product design in order to remedy the problem. Biodegradable K-Cups are now manufactured by those companies, and the customer experiences the same level of convenience as a normal K-Cup, but without the pollution waste from the plastic. The coffee may even taste better since it is not being brewed in plastic.

The resulting effect of adding a DP for sustainable packaging can be seen in the comparison of the design matrices for Design A (generic plastic K-Cup, Equation 8) and Design B (Biodegradable K-Cups, Equation 9). Both designs are coupled. How can the marketplace accept and use product designs that are seemingly coupled?

\section{Design A:}

$$
\left\{\begin{array}{c}
\mathrm{FR}_{\text {Convenient }} \\
\mathrm{FR}_{\text {LowCost }}
\end{array}\right\}=\left[\begin{array}{cc}
X & X \\
X & X
\end{array}\right]\left\{\begin{array}{c}
\mathrm{DP}_{\text {Convenient }} \\
\mathrm{DP}_{\text {LowCost }}
\end{array}\right\}
$$

\section{Design B:}

$$
\left\{\begin{array}{c}
\mathrm{FR}_{\text {Earth-Friendly }} \\
\mathrm{FR}_{\text {Convenient }} \\
\mathrm{FR}_{\text {LowCost }}
\end{array}\right\}=\left[\begin{array}{ccc}
X & X & X \\
X & X & X \\
X & X & X
\end{array}\right]\left\{\begin{array}{c}
\mathrm{DP}_{\text {Earth-Friendly }} \\
\mathrm{DP}_{\text {Convenient }} \\
\mathrm{DP}_{\text {LowCost }}
\end{array}\right\}
$$

With $\mathrm{AD}$, the designer can achieve the design intention by choosing DPs that decouple a design[7], but this decoupling can also result from customer perception and acceptance of a DP. For example, packaging coffee into single-serve plastic cups results in a higher cost per cup of coffee for the consumer, thus the choice of DP for convenience will affect the achievement of a low-cost cup of coffee, but the choice of DP for the low cost may also affect the achievement of convenience. Therefore the design is coupled, but with the sales and widespread success of single-serve coffee makers, clearly, the consumer is willing to pay more for convenience. For the consumer, there may be no significance of the increased cost for added convenience. Therefore, there is little to no relationship between between low cost and convenience as expressed by equation 10 .

\section{Customer-Perceived Design A:}

$$
\left\{\begin{array}{c}
\mathrm{FR}_{\text {Low Cost }} \\
\mathrm{FR}_{\text {Convenient }}
\end{array}\right\}=\left[\begin{array}{cc}
X & 0 \\
X & X
\end{array}\right]\left\{\begin{array}{c}
\mathrm{DP}_{\text {LowCost }} \\
\mathrm{DP}_{\text {Convenient }}
\end{array}\right\}
$$

In addition, customer perception may also affect the design matrix for Design $\mathrm{B}$ which considers the earth-friendly FR. For instance, a consumer looking to purchase a more earth-friendly K-cup may not perceive additional cost or less convenience to be a barrier to 
purchasing the product. Therefore, Design B becomes a partially coupled design as expressed by Equation 10 . Both customer-perceived designs become lower triangular.

\section{Customer-Perceived Design B:}

$$
\left\{\begin{array}{c}
\mathrm{FR}_{\text {Earth-Friendly }} \\
\mathrm{FR}_{\text {LowCost }} \\
\mathrm{FR}_{\text {Convenient }}
\end{array}\right\}=\left[\begin{array}{ccc}
X & 0 & 0 \\
X & X & 0 \\
X & X & X
\end{array}\right]\left\{\begin{array}{c}
\mathrm{DP}_{\text {Biodegradable }} \\
\mathrm{DP}_{\text {LowCost }} \\
\mathrm{DP}_{\text {Convenient }}
\end{array}\right\}
$$

The thinking is that customer perception and the acceptance of new innovations can decouple designs that were previously considered to be coupled. Design intention allows the designer the opportunity to recognize that if the customer accepts the addition of an FR, then a seemingly coupled design can become decoupled. In this way, a designer can rely on marketing to create the customer need that drives this additional FR.

\section{Conclusion}

In this paper, we have considered a number of complex kitchen-related tasks and operations in the lens of Axiomatic Design. When cooking a turkey, it advises the cook to decouple the different incompatible cooking materials: dark meat and white meat. If dis-assembly was not acceptable, the cook needs to increase the design range by brining and changing the heat-transfer between the different compositions of meat.

For apple pie, the coupling appears in the choice of fat, moisture, and its interaction with gluten in making a pie crust. The traditional recipe is high-information content because it requires tightly controlled conditions to have a crust that is flaky but can be manipulated into the proper shape. AD again asks us to find ways to uncouple these three elements by finding a different working fluid, alcohol, which separates the workability from gluten formation.

Reverse engineering of food has many similarities with traditional reverse engineering of product and system designs and AD's complexity definition may be well used. As an analog to traditional engineering, knowledge acquisition is the central theme here. Knowledge and complexity have an inverse relationship; as relevant knowledge increases, complexity is reduced. Just like a product designer that is learning while designing, a chef reconstructing a dish needs knowledge and understanding of the recipe: structured analysis in (re)evaluation supports this process.

In addition to the recipe, food preparation requires the equipment and the food as the raw materials. Innovation in both equipment and packaging design was discussed from the customer viewpoint. AD was used to describe that customer acceptance of equipment and packaging innovations can decouple designs that are coupled. The K-Cup was used to illustrate these points and further illustrates the significance and consequence of design intention.

\section{References}

[1] E. Pétursson, I.N. Karlsson, O.G. Garðarsson, P. Pálsson, V.O. Saulius Genutis, J.T. Foley, $A x$ iomatic Design of Equipment for Analysis of SMA Spring Degradation During Electronic Actuation, in Complex Systems Engineering and Development Proceedings of the 27th CIRP Design Conference, Procedia CIRP (Elsevier ScienceDirect, Cranfield University, UK, 2017), pp. 261-266, may 10-12

[2] L. Gualtieri, E. Rauch, R. Rojas, R. Vidoni, D.T. Matt, Application of Axiomatic Design for the Design of a Safe Collaborative Human-Robot Assembly Workplace, in [51], p. 01003, october. 9-11, https: //doi.org/10.1051/matecconf/201822301003

[3] K. Iino, M. Nakao, Human Design Parameters for Safety of Products and Systems, in [51], p. 01002, october. 9-11, https://doi.org/10. $1051 /$ matecconf $/ 201822301002$

[4] K. Kujawa, J. Weber, E. Puik, K. Paetzold, Exploring and Adapt! - Extending the Adapt! Method to Develop Reconfigurable Manufacturing Systems, in [51], p. 01006, october. 9-11, https:/doi.org/ 10. $1051 /$ matecconf/201822301006

[5] F. Rolli, J. Fradinho, A. Giorgetti, P. Citti, G. Arcidiacono, Axiomatic decomposition of a zero-sum game: the penalty shoot-out case, in [51], p. 01005, october. 9-11, https:/doi .org/10.1051/ matecconf $/ 201822301005$

[6] J.J. Smith, S.A. Shah, D.S. Cochran, Prevention, Early Detection, and Reversal of Type-2 Diabetes using Collective System Design, in [51], p. 01018, october. 9-11, https:/doi .org/10.1051/ matecconf $/ 201822301018$

[7] N.P. Suh, Axiomatic Design - Advances and Applications (Oxford University Press, 2001)

[8] N.P. Suh, Challenges in dealing with large systems, in [52], pp. 1-15, keynote

[9] C.M. Wettasinghe, T.H. Koh, Axiomatic design theory for the analysis, comparison, and redesign of curriculum for special education, Disability and Rehabilitation. Assistive Technology 3, 309 (2008)

[10] J.T. Foley, S. Harðardóttir, Creative Axiomatic Design, in 26th CIRP Design Conference, Procedia CIRP (Elsevier ScienceDirect, Stockholm, Sweden, 2016), pp. 688-694, jun. 15-17

[11] J.T. Foley, E. Puik, D.S. Cochran, The Faucet Reloaded: Improving Axiomatic Design by Example, in [53], p. 7, sep. 15-18

[12] H. McGee, On Food and Cooking (Scribner, 2007), revised from 1984 version

[13] A.H. Slocum, FUNdaMENTALS of Design (MIT Precision Engineering Research Group, 2008), http://pergatory.mit.edu/resources/ FUNdaMENTALS.html

[14] D.M. Vossebeld, J.T. Foley, E. Puik, The Complexity of Mapping Customer Needs ... (and the myth of a Unanimous Customer), in [51], p. 7, october. 9-11 
[15] K. Ulrich, S. Eppinger, Product Design and Development, 6th edn. (McGraw-Hill Education, 2015)

[16] N.P. Suh, The Principles of Design (Oxford University Press, 1990)

[17] N.P. Suh, Complexity (Oxford University Press, 2005)

[18] D.S. Cochran, J.T. Foley, Z. Bi, Use of the Manufacturing System Design Decomposition for Comparative Analysis and Effective Design of Production Systems, International Journal of Production Research 55, 870 (2016)

[19] E.M. Benavides, Advanced engineering design - An integrated approach (Woodhead Publishing, 2012)

[20] F.Y. Ómarsdóttir, R.B. Ólafsson, J.T. Foley, The axiomatic design of Chessmate: a chess-playing robot, in [54], pp. 213-236, sep. 21-23

[21] J.T. Foley, Tutorial: Axiomatic Design for Everyone, in [53], p. 68, sep. 15-18

[22] A. Girgenti, B. Pacifici, A. Ciappi, A. Giorgetti, $A n$ Axiomatic Design Approach for Customer Satisfaction through a Lean Start-up Framework, in [54], pp. 151-157, sep. 21-23

[23] M. Donovan, On Food and Cooking: The Science and Lore of the Kitchen, 2nd ed., Gastronomica: The Journal of Critical Food Studies 6, 117 (2006), book Review

[24] J. Bramlett, The Unconventional Thinking of Dominant Companies (CreateSpace Indpendent Publishing Platform, 2018)

[25] K. Davis, More Than a Meal (Lantern Books, New York, NY, USA, 2001)

[26] Z. Weinersmith, Saturday morning breakfast cereal comic: Dinosaur to turkey (2011), https://www. smbc-comics.com/comic/2011-11-08

[27] A.W. Schorger, The Wild Turkey: Its History and Domestication (University of Oklahoma Press, Norman, 1966)

[28] W. Bradford, Of Plymouth Plantation 1620-1647 (Modern Library, New York, 1981), first printed in entirety 1856

[29] A.H. Wright, Early Records of the Wild Turkey, The Auk: A Quarterly Journal of Ornithology 31, 334 (1914)

[30] T.L. Goodwin, W.C. Mickelberry, W.J. Stadelman, The Effect of Freezing, Method of Cooking, and Storage Time on the Tenderness of Pre-cooked and Raw Turkey Meat, Poultry Science 41, 1268 (1962)

[31] United Stated Department of Agriculture, Turkey basics: Safe cooking (2015), https://www.fsis.usda.gov/wps/portal/ fsis/topics/food-safety-education/ get-answers/food-safety-fact-sheets/ poultry-preparation/ turkey-basics-safe-cooking/CT_Index

[32] D. Papasidero, S. Pierucci, F. Manenti, L. Piazza, Heat and mass transfer in roast beef cooking. Temperature and weight loss prediction, Chemical Engineering Transations 43, 151 (2015)
[33] H. McGee, J. Mcinerney, A. Harrus, The Virtual Cook: Modeling Heat Transfer in the Kitchen, Physics Today - PHYS TODAY 52, 30 (1999)

[34] H.C. Chang, J.A. Carpenter, R.T. Toledo, Modeling Heat Transfer During Oven Roasting of Unstuffed Turkeys, Journal of Food Science 63, 257 (1998)

[35] G. Atshuller, And Suddenly the Inventor Appeared (Technical Innovation Center, 1994), translated from Rissan by Leev Shulyak

[36] Z. Weinersmith, Saturday morning breakfast cereal comic: Gmo (2018), https://www.smbc-comics. $\mathrm{com} / \mathrm{comic} / \mathrm{gmo}$

[37] G. Butler, 15 greatest deep-fried turkey disasters caught on video (2015), https: //www. oregonlive.com/cooking/2015/11/ 12_greatest_deep-fried_turkey.html

[38] J. Osias, Safe turkey deep fryer (2006), US Patent 20060272633A1

[39] R. Hays, How to Brine a Turkey, Cook's Illustrated (2004)

[40] L. Lam, Easier Roast Turkey and Gravy, Cook's Illustrated (2016)

[41] America's Test Kitchen, Recipe: Classic apple pie (1997), https://www.cooksillustrated.com/ recipes/1377-classic-apple-pie

[42] K. Eschner, Apple Pie Is Not All That American, Smithsonian (2017)

[43] K. Kohatsu, Why Are We 'As American As Apple Pie'?, Huffington Post (2017), originally published 2014

[44] J.K. Lopez-alt, Foolproof Pie Dough, Cook's Illustrated (2007)

[45] J.T. Foley, E. Puik, D.S. Cochran, Desirable Complexity, in [54], pp. 101-106, sep. 21-23

[46] E. Puik, D. Ceglarek, A Review on Information in Design, in [55]

[47] E. Puik, D. Ceglarek, The quality of a design will not exceed the knowledge of its designer; an analysis based on Axiomatic Information and the Cynefin Framework, in [52], sep. 16-18

[48] E. Puik, D. Ceglarek, A Theory of Maturity, in [55]

[49] K. Ulrich, S. Eppinger, Product Design and Development, 6th edn. (McGraw-Hill Education, New York, NY, 2015), ISBN 978-0-07-802906-6

[50] Keurig (2019), page Version ID: 894804138, https://en.wikipedia.org/w/index.php? title=Keurig\&oldid $=894804138$

[51] E. Puik, J.T. Foley, D. Cochran, M. Betasolo, eds., 12th International Conference on Axiomatic Design (ICAD) (MATEC Web of Conferences, Reykjavík, Iceland, 2018), october. 9-11

[52] M.K. Thompson, A. Giorgetti, P. Citti, D. Matt, N.P. Suh, eds., 9th International Conference on Axiomatic Design (ICAD), Vol. 34, Procedia CIRP (Elsevier ScienceDirect, Florence, Italy, 2015), sep. 16-18

[53] O. Dodoun, ed., 11th International Conference on Axiomatic Design (ICAD) (MATEC Web of Conferences, Iasi, Romania, 2017), sep. 15-18 
[54] A. Liu, ed., 10th International Conference on Axiomatic Design (ICAD), Vol. 53, Procedia CIRP (Elsevier ScienceDirect, Xi' an, Shaanxi, China, 2016), sep. 21-23
[55] M.K. Thompson, ed., 8th International Conference on Axiomatic Design (ICAD 2014), Vol. 33, CIRP (Axiomatic Design Solutions, Inc., Lisboa, Portugal, 2014) 